\title{
Influence of the mechanical properties of lime mortar on the strength of brick masonry
}

\author{
Adrian Costigan ${ }^{1}$ and Sara Pavía ${ }^{1}$ \\ ${ }^{1}$ Department of Civil, Structural \& Environmental Engineering, Trinity College Dublin, Ireland, \\ costigaf@tcd.ie,pavias@tcd.ie
}

\begin{abstract}
This paper aims at improving the quality of lime mortar masonry by understanding the mechanics of mortars and masonry and their interaction. It investigates how the mortar's compressive and flexural strengths impact the compressive and bond strength of clay brick masonry bound with calcium lime (CL) and natural hydraulic lime (NHL) mortars. It concludes that the strength of the bond has a greater impact on the compressive strength of masonry than the mortar's strength. The masonry compressive strength increased proportionally to the strength of the bond up to 6 months. A regression analysis, giving a second order equation with coefficient of determination $\left(\mathrm{R}^{2}\right)$ of 0.918 , demonstrates a strong and predictable relationship between bond strength and masonry compressive strength. It was noted that CL90s mortar masonry reaching a high bond value was stronger than that built with a stronger mortar but displaying a poorer bond. Finally, the mechanics of lime mortars and their masonry are similar. The predominantly elastic behaviour of the mortars of higher hydraulic strength compares well with the elastic and brittle behaviour of their masonry, with either little (NHL2) or non-existent plasticity (NHL3.5 and 5); in contrast, the CL90 mortar and masonry exhibit a plastic behaviour.
\end{abstract}

\section{Introduction}

Mortars influence masonry to such a great extent that they can either enhance or adversely affect the durability of masonry. It is widely accepted that, to ensure durability, historic mortars should be replaced with similar, compatible mixes. Research has focused on specifying repair mortars based on the characteristics of the originals. Rather, this work proposes to understand the mechanical properties of mortar and masonry and their interactions in order to specify mortar repairs. It does not consider the properties of the original mortar but those of the new mortars, building units and resultant masonry. It investigates compressive and bond strength of masonry bound with lime mortars of diverse hydraulic strength 
(made with non hydraulic as well as feebly, moderately and eminently hydraulic limes) and thus different stiffness and deformability.

There is no agreement on the mechanics of masonry and the reasons for failure; some authors give more importance to the mortar properties and deformation while others believe that it is the masonry units that determine failure. For example, it has been reported that mortar deformations have a greater effect on the behaviour of masonry structures than the strength/stiffness of the units [1], and that the difference in the elastic properties of unit and mortar is the precursor of failure in compression ([2] referring to Hilsdorf 1969 and McNary and Abrams 1985). In contrast, according to other authors [3], the crushing strength of the weakest brick, rather than the interaction between brick and mortar, often determines masonry strength; and this can mask the influence of the mortar's strength on the strength of the masonry. Yet other authors have stated that masonry compressive strength is not sensitive to bond strength variations when the masonry unit is stiffer than the mortar [4].

Uniaxial compression of masonry leads to a state of tri-axial compression in the mortar and of compression/biaxial tension in the unit: during compression, lime mortars expand laterally more than bricks due to their lesser stiffness, however, within masonry, the mortar is laterally confined at the brick-mortar interface. As a result, shear stresses at the interface result in an internal state of stress which consists of triaxial compression in mortar and bilateral tension coupled with uniaxial compression in bricks. This state of stress initiates vertical splitting cracks in bricks that lead to prism failure ([5] referring to Atkinson and Nolan 1983 and Drysdale et al 1994).

The strength of the bond between mortar and unit is essential, as it determines how the masonry transfers and resists stresses due to various applied loads. Water absorption has a significant influence on bond development and hence flexural strength [6,7]. Mortars of different compressive strengths but similar bond strength result in similar masonry compressive strength; and both the bond strength and the masonry's compressive strength are not significantly impacted by the strength of the mortar $[5,8]$. Current literature indicates that an increase in bond strength, while keeping the mortar strength constant, results in an increase in the compressive strength of the masonry [9]. The rate of brick absorption and the mortar water retention are essential to bond development, as they control moisture transport at the interface allowing for the formation of the hydrates that enable bonding [10]. Results by [11] agree with these, stating that the main mortar parameter that influences bond strength of NHL-mortar masonry is water retention, followed by water content and, finally, the mortar's hydraulic strength. These authors demonstrated that the strength of the bond is not determined by the hydraulic strength of the binder, but it increases with the mortar's water retention. 


\section{Materials and methods}

\section{$2.1 \quad$ Materials}

Mortars were made with CL90-s and three NHLs of hydraulic strengths 2, 3.5 and $5 \mathrm{MPa}$. A siliceous aggregate (particle size distribution ranging within the standard limits [12]) and moulded, frogged clay bricks (Table 1) were used. A binder: aggregate ratio of 1:3 by weight was kept constant as prescribed by the standards $[12,13]$. In all compression and flexural tests the measured values are the arithmetic mean of three specimens; and the mean of five values for the flexural bond strength tests.

\subsection{Mixing and curing. Initial flow and workability}

Water content is the main contributor to mortar workability and determines initial flow, a measurement that takes into account variables affecting workability, such as porosity, size/shape of aggregate, binder type and aggregate/binder [13]. Based on previous research [14] an initial flow of $165 \pm 3 \mathrm{~mm}$ was specified for all mortars to ensure adequate workability. Initial flow was measured, and the water content reported as the ratio of water to total mortar by mass in accordance with EN 459 [14]. Mixing, curing and storage were in accordance with EN 459 [14]: at $20^{\circ} \mathrm{C}$ and $65 \% \mathrm{RH}$ for CL90s; 7 days at $95 \%$ and 21 days at $65 \%$ for NHL2 and 3.5; and 95\% RH for NHL5. Wallettes were constructed in accordance with EN 1052 for compressive, flexural and bond strength respectively [15-17] and cured and stored in exactly the same conditions as the corresponding mortar.

Table 1 Brick Characteristics

\begin{tabular}{ll}
\hline Property $\quad$ Testing standard: & EN 771-1 :2003) \\
\hline Compressive Strength $\left(\mathrm{N} / \mathrm{mm}^{2}\right)$ & $\geq 12$ \\
Water absorption $(\%)$ & Max 15 \\
Unit size $(\mathrm{mm}) /$ Size tolerance & $215 \times 102.5 \times 65 / \mathrm{T} 2-\mathrm{R} 1$ \\
Gross / net density $\left(\mathrm{kg} / \mathrm{m}^{3}\right)$ & $1630 / 1920$ \\
Initial rate of absorption $\left(\mathrm{kg} / \mathrm{m}^{2} /\right.$ minute) & 1.0 \\
\hline
\end{tabular}

\subsection{Mechanical properties of mortar}

During the compression and flexural mortar tests, the force-strain curves were recorded in order to study the mechanical behavior of the mortars under load application.

Compressive $\left(\mathrm{R}_{\mathrm{c}},\right)$ and flexural $\left(\mathrm{R}_{\mathrm{f}},\right)$ strength were determined on prisms as specified in the standards using equ. 1 and $2[12,13]$. Where: $F_{c}$ is the max load at 
fracture $(\mathrm{N}) ; 6400$-area of the face $\left(\mathrm{mm}^{2}\right) ; \mathrm{F}_{\mathrm{f}}$-load at fracture $(\mathrm{N})$; b-prism section $\left(\mathrm{mm}^{2}\right) ; 1$-distance between supports $(\mathrm{mm})$.

$$
\begin{array}{cc}
R_{c}=\frac{F_{c}}{6400} & \left(\mathrm{~N} / \mathrm{mm}^{2}\right) \\
R_{f}=\frac{1.5 \times F_{f} \times l}{b^{3}} & \left(\mathrm{~N} / \mathrm{mm}^{2}\right)
\end{array}
$$

\subsection{Compressive, flexural and bond strength of masonry}

The compressive and flexural strengths were tested according to EN 1052 parts 1 and 2 respectively $[15,16]$ on masonry wallettes built according to the aforementioned standard (Fig. 1). During the compression and flexural masonry tests, force-strain curves were recorded with the strain values provided by lateral variable displacement transducers continuously monitoring the change in length on application of the load. Eq. 5 and 6 were used to determine the compressive $\left(f_{i}\right)$ and characteristic compressive strength. Where: $\mathrm{F}_{\mathrm{i}, \max }-\max$ load $(\mathrm{N})$; A-loaded cross-section $\left(\mathrm{mm}^{2}\right)$. The flexural bond strength was determined with the bond wrench test according to EN 1052, using five-brick-high bonded prism stacks (Fig. 2) [13, 17].

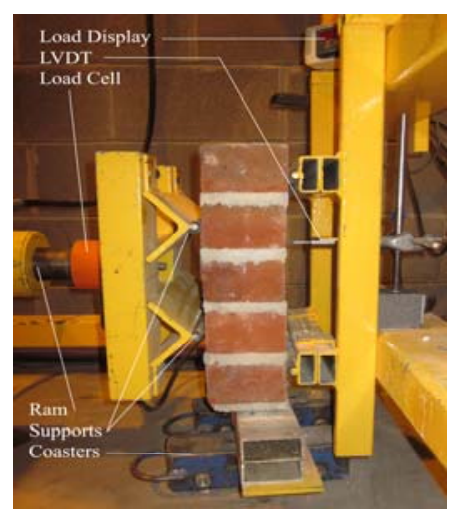

Fig. 1 Flexural strength masonry test set up

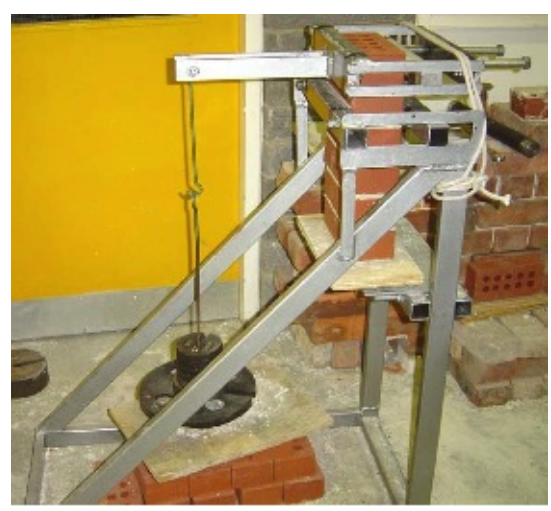

Fig. 2 Bond strength test set up

$$
\begin{gathered}
f_{i}=\frac{F_{i, \max }}{A_{i}} \quad\left(\mathrm{~N} / \mathrm{mm}^{2}\right) \\
f_{k}=\frac{f}{1.2} \text { or } f_{k}=f_{i, \text { min }} \quad\left(\mathrm{N} / \mathrm{mm}^{2}\right) \text { whichever is smaller }
\end{gathered}
$$




\section{Results and discussion}

\subsection{Properties of lime mortars}

As expected (Figs. 3, 4), most hydraulic limes build strength faster and reach a higher ultimate strength. The NHL3.5 and 5 mortars gain compressive strength at similar rates throughout curing while the NHL2 mortar increases compressive strength by only $18 \%$ between 1 and 2 months. The flexural strength of the CL90 mortar increases by $64 \%$ between 1 and 2 months and by a factor of four between 2 and 6. The flexural strength of NHL3.5 mortar also increases substantially between 2 and 6 months (by a factor of three) while the NHL5 mortar increases by $35 \%$ between 1 and 2 months and again by $35 \%$ between 2 and 6 months.

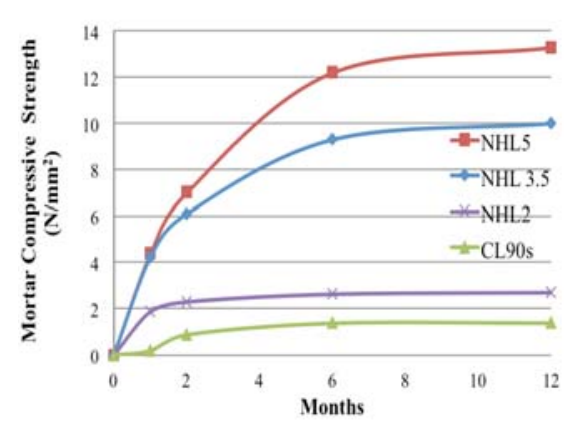

Fig. 3 Compressive strength of mortars

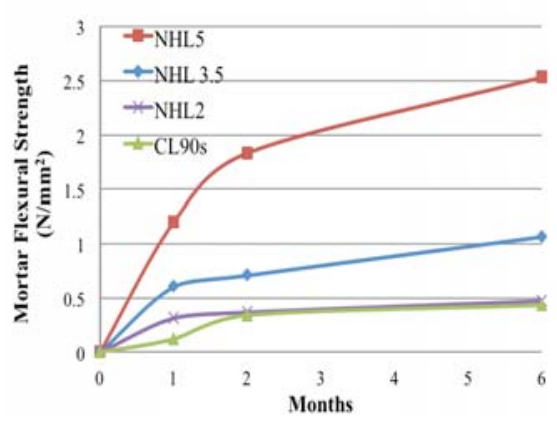

Fig. 4 Flexural strength of mortars

The stress-strain results revealed that, under compression, the mortars of higher hydraulic strength exhibit a predominantly elastic behaviour whereas the NHL2 and CL90 mortars behave in a more plastic manner (Fig. 5). According to Figure 5, under compression, the NHL5 mortar displays the greatest elastic region while the NHL2 and CL90 mortars show the smallest elastic regions and the greatest plasticity. Therefore, extent of the elastic region increases while the plastic region tends to decrease as the mortar's compressive strength increases.

In flexion, the extent of the elastic region increases with the mortar's flexural strength (Fig. 6); and most mortars do not show a plastic region but strain linearly on stress application until failure occurs, and failure appears suddenly with no plastic deformation. In flexion, the CL90-s mortar strains significantly before failing at a relatively low strength when compared to the other mortars. 


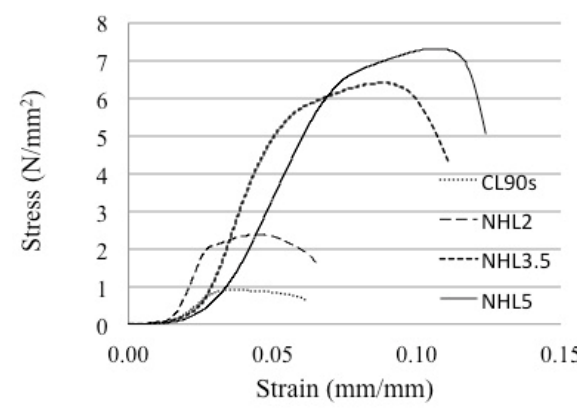

Fig. 5 Deformability of mortars under compression after 56 days of curing

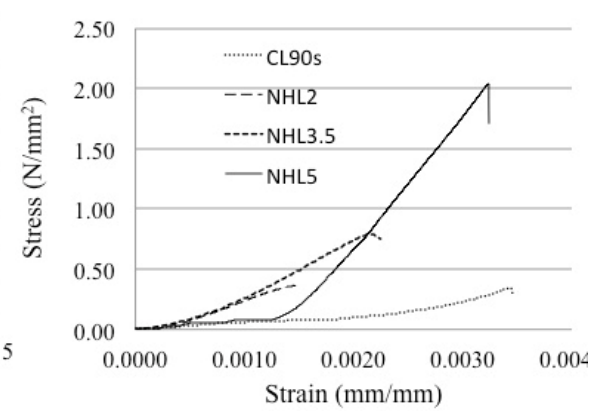

Fig. 6 Deformability of mortars under flexion after 56 days of curing

\subsection{Properties of masonry}

The compressive strength development of NHL5 and 3.5 mortar masonry is similar (Fig. 7). Initially, they gain strength at the same rate; however after 28 days the NHL3.5 masonry gain is faster, becoming $6 \%$ stronger than the NHL5 masonry at 6 months and $5 \%$ at one year. This is due to the higher water demand of the NHL5 so that, at equal flows, the NHL3.5 mortar has more water available to develop a stronger bond.

The NHL5 and 3.5 masonry gain strength quickly; at 56 days both have reached over $70 \%$ of their one-year strength. NHL2 shows a similar trend as significant gains occur in the first 28 days. In contrast, the largest gain of the CL90 masonry occurs between 2 and 6 months (at 150\%), having gained over $90 \%$ of its one year strength at 6 months.

According to the bond strength results, $60-90 \%$ of the ultimate bond strength is achieved after 56 days (Fig. 8): at 2 months the CL90 masonry has reached 36\% of its total one year bond strength, while NHL5 and 3.5 have reached $65 \%$; the CL90 masonry bond strength at 6 months equals that of the NHL2 masonry at 2 months. However, the bond strength of the NHL3.5 masonry is greater than that of the NHL5 masonry ( $8 \%$ greater at six months).

As for the mortars (Figs. 5-6), the stress-strain curves of masonry in Figure 9 evidenced the plastic behaviour of the CL90s masonry, supporting small stress increases while progressively deforming and displaying a short elastic region. In contrast, all the NHL mortar masonry displays large elastic regions and either little (NHL2) or no plasticity (NHL3.5 and 5). The results also showed that the NHL3.5 is stiffer than the NHL5 masonry and deflects less under the same applied stress. 


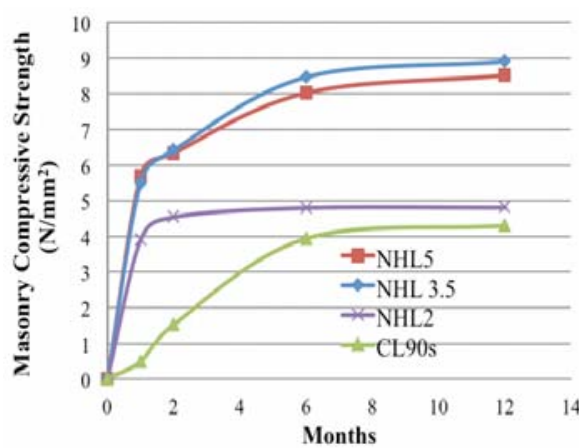

Fig. 7 Compressive strength of masonry

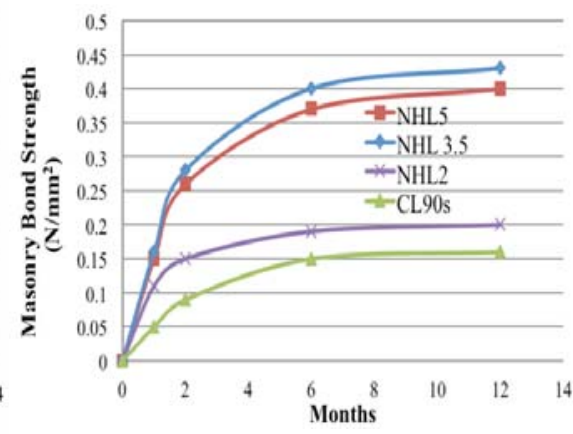

Fig. 8 Bond strength development over time

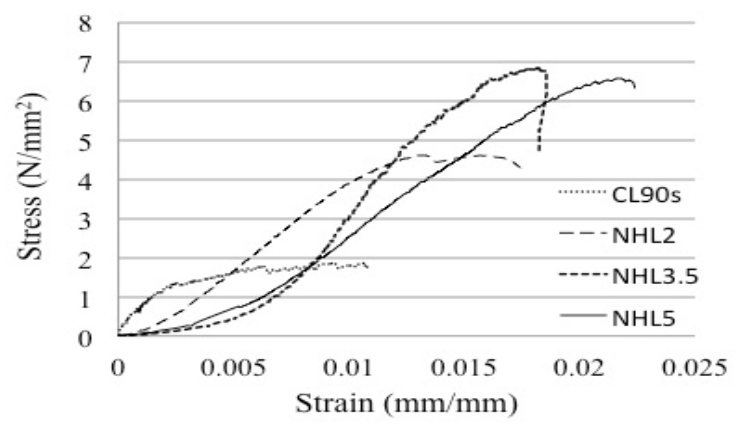

Fig. 9 Deformability of CL90s, NHL2, NHL3.5 and NHL5 masonry under compression at 56 days

\subsection{Influence of mortar properties on masonry strength}

The results evidenced that large increases in mortar compressive strength do not lead to significant increases in masonry compressive strength (Fig. 10). This agrees with previous authors [3, 6] stating that masonry compressive strength is not significantly impacted by mortar strength. As can be seen from the results, between 28 and 56 days, the compressive strength of NHL5 mortar increases by $60 \%$ however, the corresponding masonry only increases by $11 \%$. The same relationship is maintained between 2 and 6 months, where the mortar strength increases by $75 \%$ and the masonry's only by $30 \%$. The regression analysis evidences that the values fit well with a polynomial line $\left(\mathrm{R}^{2}\right.$ value of 0.88$)$, Figure 11. This indicates a strong, non-linear relationship between mortar and masonry strength, with a maximum masonry strength of $8.9 \mathrm{~N} / \mathrm{mm}^{2}$ for this particular brick. 


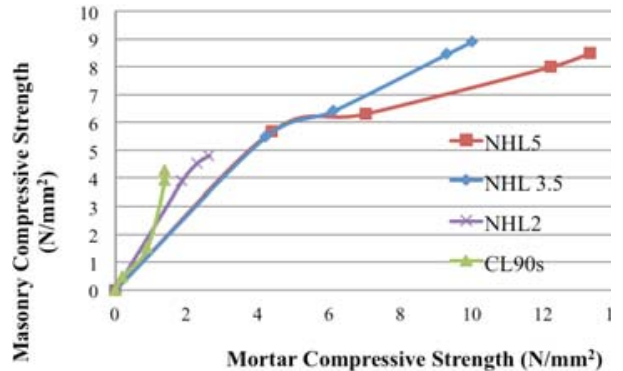

Fig. 10 Influence of mortar compressive strength on masonry compressive strength

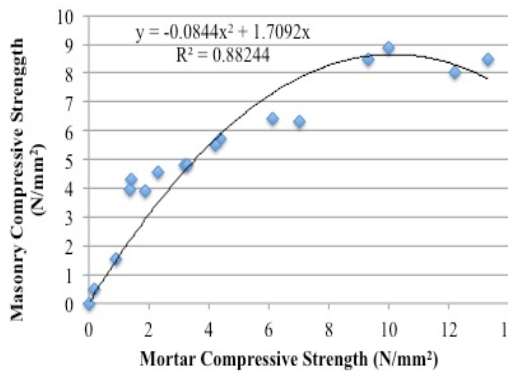

Fig. 11 Regression analysis of data in Figure 10

According to the results in Figure 10, the mortars of higher hydraulic strengths (NHL5 and 3.5) are stronger than their corresponding masonry: after a year, the NHL5 mortar is stronger in compression $\left(12.21 \mathrm{~N} / \mathrm{mm}^{2}\right)$ than its masonry $(8.01$ $\mathrm{N} / \mathrm{mm}^{2}$ ); and NHL3.5 mortars follow the same trend (a $10 \mathrm{~N} / \mathrm{mm}^{2}$ mortar vs a 8.9 $\mathrm{N} / \mathrm{mm}^{2}$ masonry). In contrast, NHL2 and CL90s show the opposite trend: the mortars have a mean 56 day compressive strength of 2.29 and $1.39 \mathrm{~N} / \mathrm{mm}^{2}$ respectively while their corresponding masonry strengths are much higher, at 4.54 and $4.3 \mathrm{~N} / \mathrm{mm}^{2}$ respectively.

In addition, the hydraulic strength of the lime (thus mortar strength) and the bond strength of the resultant masonry tend to display an inverse relationship (Fig. 12). As it can be seen from this figure, the lower the hydraulic strength of the lime (CL90s and NHL2 mortars) the faster the rate of bond strength increase therefore the bond develops faster in the mortars of lower hydraulic strength.

In relation to the impact of the mortar's flexural strength on the compressive and bond strength of masonry (Figs. 13 and 14 respectively). In general, the lower the hydraulic strength of the lime, the stronger the impact of the flexural strength of the mortar on the compressive and bond strength of the masonry.

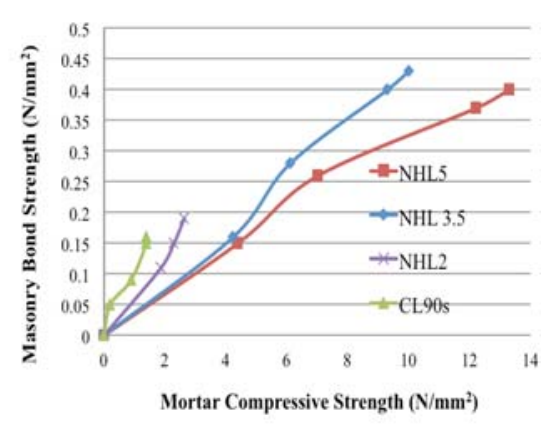

Fig. 12 Influence of mortar compressive strength on masonry bond strength

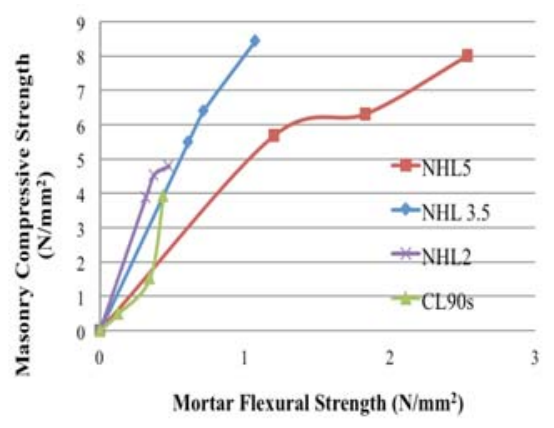

Fig. 13 Influence of mortar flexural strength on masonry compressive strength 


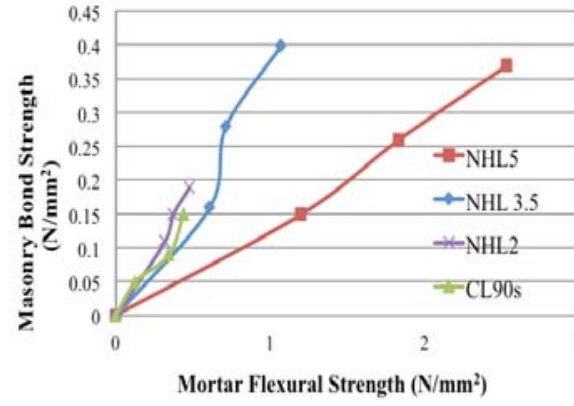

Fig. 14 Influence of mortar flexural strength on masonry bond strength

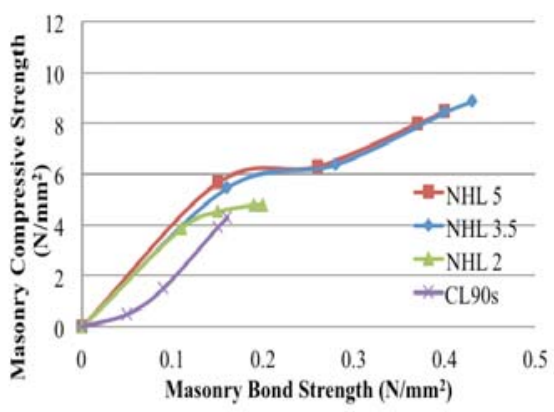

Fig. 15 Influence of bond strength on masonry compressive strength

As it can be seen from the results, bond strength has a much stronger relationship with the masonry compressive strength than mortar strength (Figs. 10, 15-17). Statistical analysis (Fig. 16) shows a non-linear relationship and a $\mathrm{R}^{2}$ value of 0.92 at $5 \%$ CI. This indicates that these two properties (masonry bond and compressive strength) are very closely related to each other. In addition, when only the NHL mortar masonry is considered, the best fit becomes linear (Fig. 17) with an $R^{2}$ value of 0.94 ; when bond strength ranges between 0.1 and $0.4 \mathrm{~N} / \mathrm{mm}^{2}$, there is a clear linear relationship between the bond and the compressive strength of the masonry. This evidences that the bond strength of higher strength mortars has a greater impact on the masonry compressive strength. The results also revealed that a low-strength mortar (CL90) with a good bond (Fig. 15) performs better than a strong mortar with a poorer bond: CL90 masonry with good bond $\left(0.15 \mathrm{~N} / \mathrm{mm}^{2}\right)$ reaches $4 \mathrm{~N} / \mathrm{mm}^{2}$ compressive strength, whereas hydraulic mortar masonry with a poorer bond $\left(0.1 \mathrm{~N} / \mathrm{mm}^{2}\right.$ or under $)$ does not reach this value. The above evidences that bond strength strongly impacts the compressive strength of masonry, agreeing with previous authors [7].

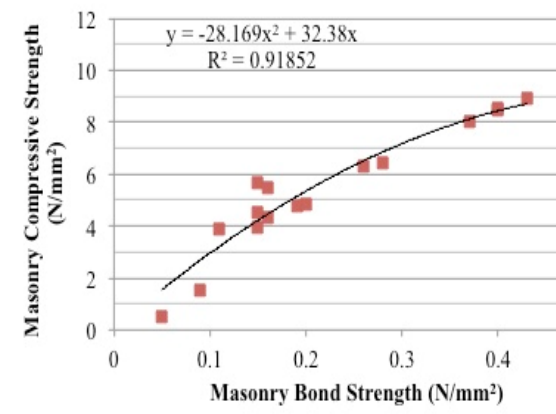

Fig. 16 Nonlinear regression analysis of data in figure 15 including all mortars

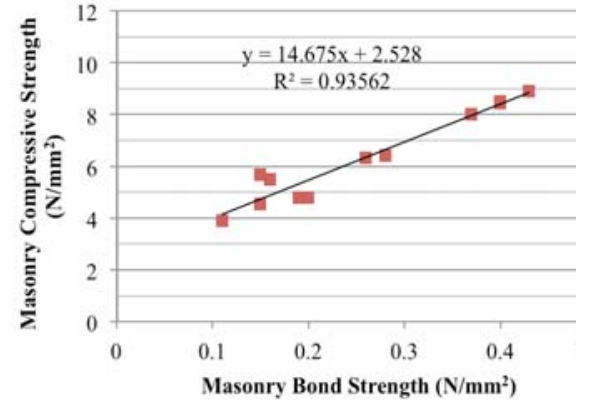

Fig. 17 Linear regression analysis of data in figure 15 including NHL mortars only 


\section{Conclusion}

The mechanics of lime mortar and lime mortar masonry are similar in compression: the mortars of higher hydraulic strength exhibit a predominantly elastic behaviour whereas the NHL2 and CL90 mortars behave in a more plastic manner. Similarly, the results evidenced the plastic behaviour of the CL90 masonry (with a short elastic region) against the elastic and brittle behaviour of the NHL masonry, with either little (NHL2) or non-existent plasticity (NHL3.5/5).

This paper concludes that masonry compressive strength is more determined by the strength of the bond rather than by the mortar's compressive strength. This is supported by the following conclusions:

- Increasing mortar strength does not significantly increase masonry strength:

o The compressive strength of NHL 5 mortar increases by $60 \%$ (between 1 and 2 months) and 75\% (between 2 and 6) while the corresponding masonry only increases strength by $30 \%$ and $11 \%$ respectively.

o A mortar of lower hydraulic strength can deliver stronger masonry than an eminently hydraulic mortar: the compressive and bond strengths of NHL3.5 masonry are greater than those of NHL5 masonry, while the NHL3.5 mortar strengths are lower than those of the NHL5 mortar.

- A low-strength mortar (CL90) which has developed a good bond delivers stronger masonry than a stronger mortar with a poorer bond.

\section{Acknowledgements}

The authors thank Paul McMahon, Architectural Heritage Division, Office of Public Works, for supporting this project. All testing was carried out in the Dept. of Civil Engineering, Trinity College Dublin. The authors thank Chris O’Donovan, Dr. Kevin Ryan and Dave McAuley for their assistance with testing; and The Traditional Lime Company, St Astier/CESA Limes, Clogrenanne Lime Ltd and Kingscourt brick for donating materials.

\section{References}

1. Boothby TE (2001) Analysis of masonry arches and vaults. Prog. Struct. Eng. Mater. 3, 246-256

2. Zucchini A, Lourenzo PB (2006) Mechanics of masonry in compression: Results from a homogeneisation approach. Computers and Structures 85: 193-204

3. Gumeste KS, Venkatarama Reddy BV, (2007) Strength and elasticity of brick masonry prisms and wallettes under compression. Mat \& Struct. 29: 241-253 
4. Venkatarama Reddy BV, Vyas Uday CV (2008). Influence of shear bond strength on compressive strength and stress-strain of masonry. Mat \& Struct 41: 1697-1712

5. Kaushik HB, Rai DC, Jain SK (2007) Stress-Strain Characteristics of Clay Brick Masonry under Uniaxial Compression ASCE 19:9, 728-739

6. Hedstrom EG, Tarhini KM, Thomas RD et al (1991) Flexural bond strength of concrete masonry prisms using PC and hydrated lime mortars. Mason Soc J 9(2):8-23

7. Portland Cement Association (PCA) (1994) Bond strength testing of masonry. Masonry Information, Skokie, Illinois

8. Venumadhava Rao K, Venkatarama Reddy BV, Jagadish KS (1995) Influence of flexural bond strength on the compressive strength of masonry. Proc. Nat. Conf. on Civil Eng. Materials and Structures, Osmania Univ., Hyderabad, India, 103-108

9. Sarangapani G, Venkatarama Reddy BV, Jagadish KS (2005) Brick-mortar bond and masonry compressive Strength. J Mater Civil Eng (ASCE) 17(2):229-237

10. Groot CJWS (1993) Effects of water on mortar brick bond. PhD thesis, University of Delft, Delft, The Netherlands

11. Pavía S, Hanley R (2010) Flexural bond strength of natural hydraulic lime mortar and clay brick. Materials and Structures, 43(7): 913-922. doi:10.1617/s11527-009-9555-2.

12. EN 196-1 (2005) Method of testing cement. Determination of strength

13. EN 459-2 (2001) Building lime. Part 2. Test methods

14. Hanley R, Pavía S (2008) A study of the workability of natural hydraulic lime mortars and its influence on strength, Materials and Structures, 41 (2) 373-381 doi:10.1617/s11527-0079250-0

15. EN 1052-1 (1999) Method of test masonry: Determination of compressive strength

16. EN 1052 -2 (1999) Method of test masonry: Determination of flexural strength

17. EN 1052 -5 (2005) Method of test masonry: Determination of bond strength 
